\title{
New Zealand Snow Sports Injury Trends Over Five Winter Seasons 2010-2014
}

\author{
Brenda A. Costa-Scorse, Will G. Hopkins, John Cronin, and Eadric Bressel
}

\begin{abstract}
Ski patrol national incident data were analysed in New Zealand for alpine skiing and snowboarding injuries from 4 June 2010 to 9 November 2014. Over five winter seasons, there were 5,861,643 visitations and 18,382 incidents. The injury rate per 1000 skier/boarder days was relatively constant $(3.2,3.3,3.4,2.7$, and 3.1, respectively). Falls accounted for the injury mechanism in $74.3 \%$ of all injuries. Four died after catastrophic falls (two skiing, two snowboarding). Overall, more knee injuries occurred skiing in soft snow conditions than hard (55 vs. 45\%). Advanced skiers were 2.2 times more likely to sustain a knee injury with nonrelease of the ski-binding in hard snow surface conditions than when the ski-binding released. Despite increased helmet usage (42-83\%), there was a very likely increase in concussion $(1.29,99 \%$ CI 1.06-1.57). Hard snow conditions increased wrist injuries for both intermediate and novice snowboarders (30 and 12\%, respectively). Wrist protection was most likely to be beneficial in preventing wrist injuries (hazard ratio $0.65,99 \%$ CI O.54-0.79). Good visibility compared to poor visibility led to a twofold increase in injuries. Increased slope congestion, changes in direction to avoid collision with others and speed were possible contributing factors. Collisions accounted for $9.6 \%$ of all injuries. Going forward New Zealand injury prevention initiatives need to be multifaceted. Recreational skiers need to ski on torque-tested equipment with release settings that are a match for current physical parameters, style, and the ability to ski in different snow surface conditions. Further research is
\end{abstract}

\footnotetext{
B.A. Costa-Scorse $(\square)$

Sports Performance Research Institute New Zealand (SPRINZ), AUT University, Auckland, New Zealand

e-mail: brenda.costa-scorse@aut.ac.nz

W.G. Hopkins

Institute of Sport, Exercise and Active Living, Victoria University, Melbourne, VIC, Australia

J. Cronin

Sports Performance Research Institute New Zealand (SPRINZ), AUT University, Auckland, New Zealand

School of Exercise, Biomedical and Health Science, Edith Cowan University, Perth, WA, Australia

E. Bressel

Utah State University, Logan, UT, USA
} 
needed to determine whether wearing a helmet increases reckless behaviour in some age groups. An international standard for snow sports wrist protectors with proven dimensions is also needed before ski areas can make any further investment in wrist protectors.

Keywords Skiing $\bullet$ Snowboarding $\bullet$ Injury $\bullet$ Mechanisms $\bullet$ Trends

\section{Introduction}

Injury surveillance is a requisite for understanding the injury problem in alpine skiing and snowboarding [1]. Historically, ski areas have monitored incidents in-house and Ski Areas Association New Zealand (SAANZ) has determined collaborative injury prevention endeavour with the support of technical reports. In 2005, all ski areas moved from recording injury incidents on a SAANZ paper-based incident reporting form to a computerised incident reporting system managed on behalf of SAANZ by the New Zealand Mountain Safety Council. Electronic incident data collection made it possible to undertake this first longitudinal skiing and snowboarding injury study. The findings from this study will provide SAANZ with more comprehensive evidence to determine, where injury prevention energy and resources should be focussed.

\section{Objectives}

Describe the injury rates and trends in snow sports in New Zealand over five winters to inform the development of a national injury prevention strategy.

\section{Methods}

The Auckland University of Technology ethics committee approved the study-reference 14/146. Ski patrollers, nurses, doctors, and radiographers completed incident reporting forms for all injuries at all commercial ski areas throughout New Zealand. Anonymised data were entered into the electronic database each week of each winter season over 5 years. The NZ Mountain Safety Council maintained the National Incident Database (NID). SAANZ provided ticket sale records and season pass use for each ski area. Demographic data from SAANZ national consumer satisfaction surveys (2007-2009) were supplied in excel. Bare-head and helmet wear counts were undertaken at chairlifts at two major ski areas in 2010 and 2015. Retrospective analyses were performed with the Statistical Analysis System (SAS). Uncertainties 
in the true values of the outcomes were assessed using magnitude-based inferences. For precision, 99\% confidence intervals were computed in SAS. Six approaches were taken in the analyses. Trends in annual incidence rates per 1000 skier/boarder days were determined by summing the injuries at each ski area for each year, then modelling the count in each year with Poisson regression using ticket sales and estimated season pass use. The proportions of skiers, snowboarders, females, and males were determined in excel using SAANZ customer surveys $(25,910)$.

The effect of snow conditions and visibility on predicting injury types was analysed by limiting the data to the six major ski areas that had $82 \%$ of the skier/boarder days. As there were always injuries on any day that the ski area was open this strategy avoided the bias that would arise from a given snow or sky condition reducing the injury rate such that no injuries occurred on some days. Hard snow or icy conditions existed when a ski patroller in ski boots could not make an impression in the snowpack. The soft or spring conditions description was used on days when the surface easily permitted leaving a ski-boot impression in the snow. Cloud cover provided effect of visibility data on injury incidence. Clear skies or scattered cloud cover determined good visibility. Poor visibility was determined by overcast conditions with full cloud cover leading to flat light or white out conditions with snow falling, mist, or rain.

Logistical regression was used to analyse the effect of snow condition, visibility, skiing or snowboarding activity, and the ability on the proportions of a given type of injury (e.g. head) and type of incident (e.g. falls, jumps, collisions). Deaths were counted. Injured skiers' self-reported when the ski-binding released during the incident or did not release. Skier accounts of the ski-binding pre-releasing in normal skiing manoeuvres were also included in the three level analysis of the effect of binding release. Probabilistic terms were used to describe the true value of changes in the mechanism (type of incident) over the 5-year period. Where the true value could be substantial in both a positive and negative sense, the result was unclear; otherwise, results were clear and the inference was described as likely trivial, possibly trivial, trivial, likely or a very likely increase or decrease [2].

The effect of helmet use on head injuries (cases) was determined by using other injuries as controls; a method previously applied in an investigation on the relation of head, face, and neck injury in skiers wearing helmets [3, 4]. A hazard ratio was obtained using a Poisson regression model of those that were head injured (using helmets)/(those not using helmets) divided by those that were non-head injured (using helmets)/(those not using helmets). The effect of wrist protection was examined in the same manner.

\section{Results}

Over five winters 5,861,643 people were active in snow sports at New Zealand ski areas and 18,382 incidents were registered. New Zealand injury trends per 1000 skier/boarder days were 3.2, 3.3, 3.4, 2.7, and 3.1, respectively (2010-2014). There 
was most likely a trivial decline in injuries over this period $(-3 \%, 99 \%$ confidence interval -9 to $3 \%$ ). The proportions of people active in each sport were determined from 25,911 SAANZ surveys: $61 \%$ skiers, $32.4 \%$ snowboarders, and $6.6 \%$ both ski and snowboard. No data was collected on the number of people tubing at ski areas.

Knee injuries were the most common injury overall (see Fig. 1). Over two-thirds of knee injuries occurred in skiers when compared with snowboarders and others (tubing/hiking) (76, 21, and 3\%, respectively). There was no significant difference in the frequency of back injury between skier and snowboarders; $36 \%$ occurred in the cervical/thoracic region; and $64 \%$ in the lumbar/sacral region. Wrist injuries were more common in snowboarders (80\%). Snowboarders accounted for 52\% of the head injuries, skiing $43 \%$, and 5\% were attributed to other activities. Shoulder injuries occurred more often in snowboarders $(61 \%)$. Clavicle injuries were also more prevalent in snowboarders (64\%). Conversely, $74 \%$ of injuries to the lower leg occurred during skiing.

SAANZ customer survey data indicated that the percentage of male skiers was $53 \%$, female skiers $47 \%$ compared to $61 \%$ male and $39 \%$ female snowboarders. Female skiers injured the knee more frequently than male skiers (65\% vs. $35 \%$ ). Nonrelease of the ski-binding resulted in knee injury in skiers more often than release (see Table 1). More knee injuries occurred in soft snow conditions than hard (55\% vs. $45 \%$ ). The rates of knee injuries either in non-release or release were highest in intermediate skiers (45\%), followed by novices (30\%) then advanced skiers (25\%).

In $2010,42 \%$ of skiers and snowboarders wore helmets; this increased to $83 \%$ in 2015 (skiers $84 \%$ and snowboarders $79 \%$ ). Concussion very likely increased over the 5 years $(1.29,99 \%$ CI 1.06-1.57). By age, 24-32 years olds were less likely to be wearing a helmet when head injured (see Fig. 2). The mean ages for each quartile were 12 years. (SD 3), 20 years. (SD 2), 27 years. (SD 2), and 47 years. (SD 10).

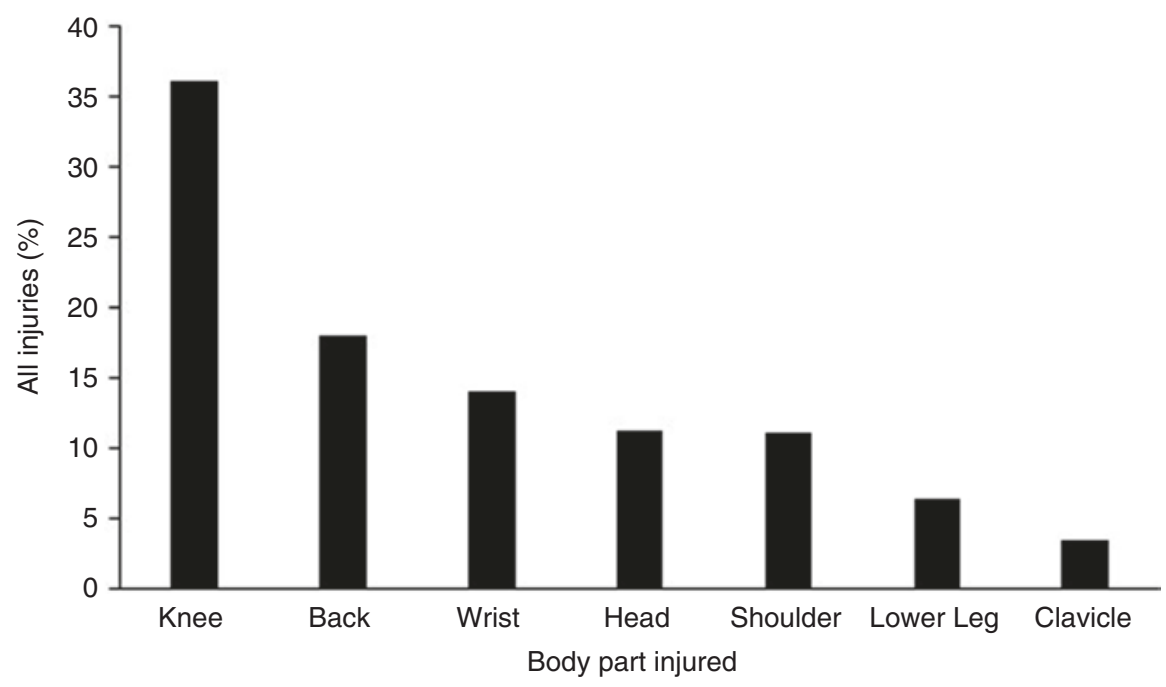

Fig. 1 Body part injured in all snow sports 
Table 1 Equipment effects on knee injuries by snow surface condition and skier ability

\begin{tabular}{|c|c|c|c|c|}
\hline & \multirow[b]{2}{*}{ Non-release } & \multirow[b]{2}{*}{ Release } & \multicolumn{2}{|c|}{ Difference (non-release/release) } \\
\hline & & & Effect; 99\% CI & Inference \\
\hline \multicolumn{5}{|c|}{ Advanced Skier } \\
\hline Soft snow & $30.7 \%(n=430)$ & $21.2 \%(n=420)$ & $1.5 ; 1.2-1.7$ & $\uparrow * * *$ \\
\hline Hard snow & $27.7 \%(n=415)$ & $12.9 \%(n=364)$ & $2.2 ; 1.7-2.7$ & $\uparrow * * * *$ \\
\hline \multicolumn{5}{|c|}{ Intermediate Skier } \\
\hline Soft snow & $44.9 \%(n=847)$ & $29 \%(n=734)$ & $1.6 ; 1.4-1.7$ & $\uparrow * * * *$ \\
\hline Hard snow & $37.2 \%(n=675)$ & $23.1 \%(n=606)$ & $1.6 ; 1.4-1.8$ & $\uparrow * * * *$ \\
\hline \multicolumn{5}{|c|}{ Novice Skier } \\
\hline Soft snow & $46.8 \%(n=662)$ & $38.2 \%(n=448)$ & $1.2 ; 1.1-1.36$ & $\uparrow * *$ \\
\hline Hard snow & $36.4 \%(n=495)$ & $33.3 \%(n=315)$ & $1.1 ; 0.9-1.3$ & $\uparrow *$ \\
\hline
\end{tabular}

Key Asterisks indicate effects clear at the $99 \%$ level and likelihood that the true effect is substantial, as follows: *possible, ${ }^{* * l i k e l y, ~}{ }^{* * *}$ very likely, $* * * *$ most likely

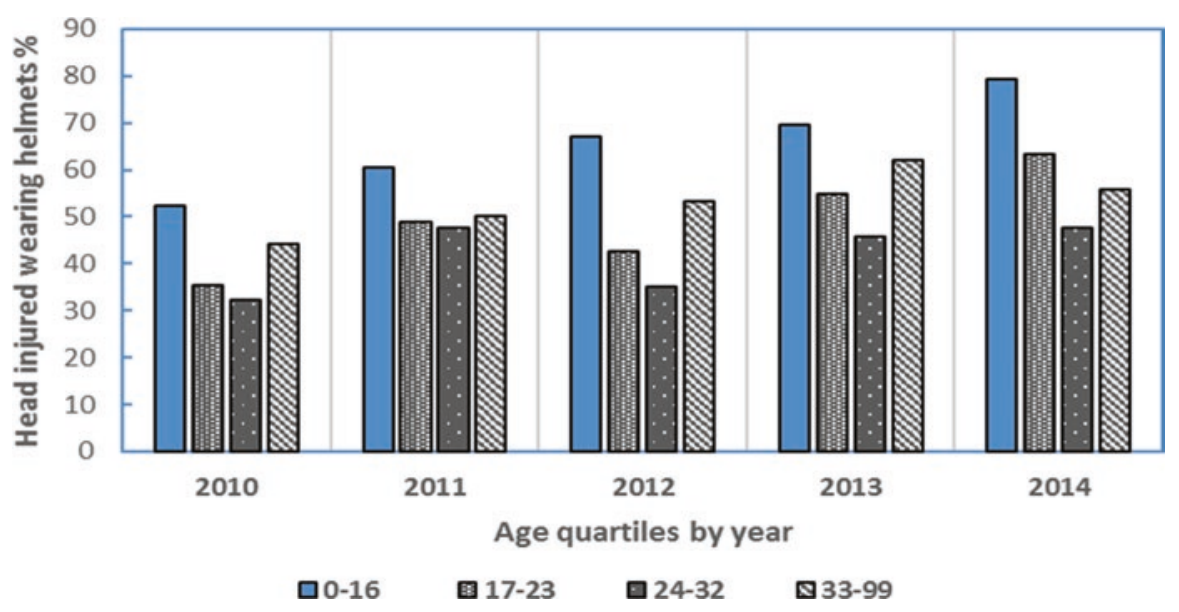

Fig. 2 Head injured wearing a helmet by age group and year

Head injury was higher in advanced and intermediate skiers wearing helmets than novices; 23, 25, and 10\%, respectively. For helmet-wearing snowboarders, head injury increased in advanced, intermediate, and novice snowboarders by 41 , 29 , and $30 \%$, respectively (when compared with those not wearing a helmet). Overall, there was a $26 \%$ increased risk of head injury in skiers wearing helmets (hazard ratio $1.26,99 \%$ CI 1.05-1.52) and a 36\% increase in head injury in snowboarders wearing helmets (hazard ratio 1.36, 1.05-1.52).

There was a very likely increase in wrist injuries in intermediate snowboarders in hard snow when compared with soft snow conditions (hazard ratio 1.3, 99\% CI 1.17-1.45). Novice snowboarders had a possible increase in the likelihood of wrist injury in hard snow conditions (hazard ratio 1.12, 99\% CI 1.02-1.21). Regardless of whether snowboarders were in a terrain park or in open mountain terrain, wrist protection was most likely beneficial in preventing wrist injuries (hazard ratio 0.65, 99\% CI O.54-0.79). 


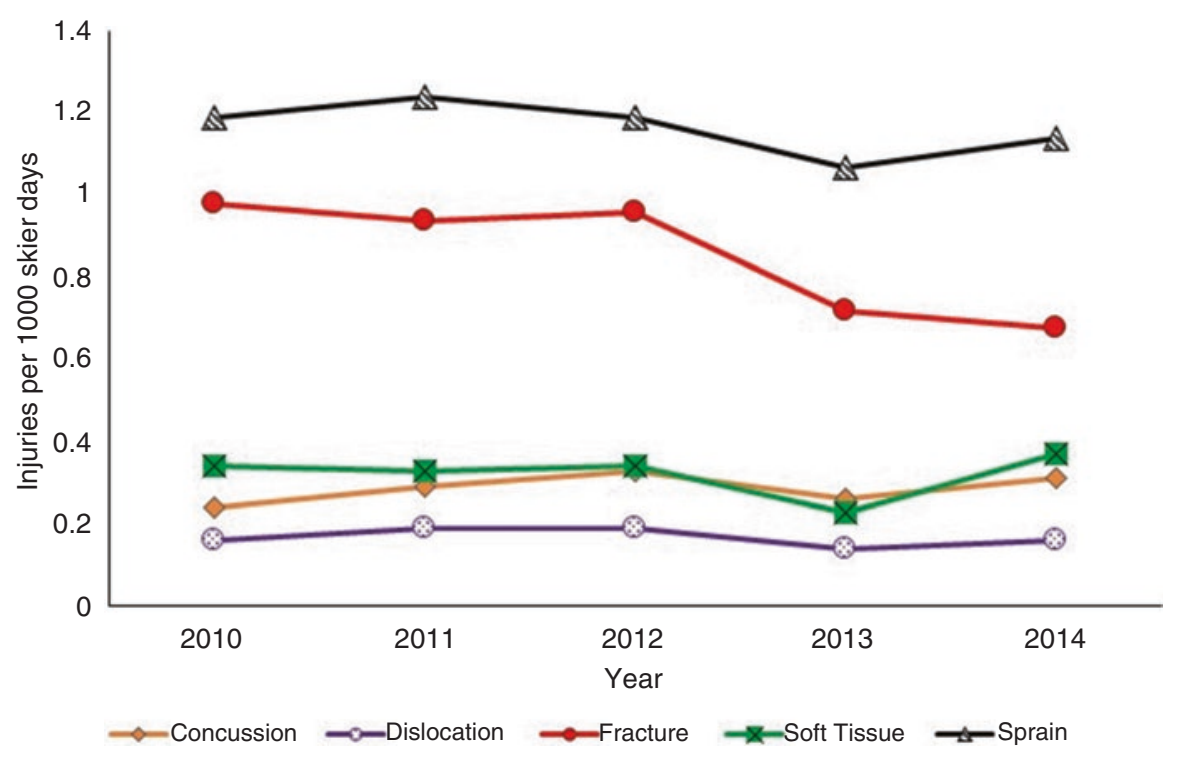

Fig. 3 Types of injury in skiing and snowboarding

The combined skiing and snowboarding results for types of injury are detailed in Fig. 3. Fractures declined by 0.3 per 1000 skier/boarder days. There was no decline in the incidence of concussion, dislocation, soft tissue injuries, or sprains.

Falls accounted for $74.3 \%$ of incident types with no difference between skiers and snowboarders; collisions $9.6 \%$-snowboarders were more commonly injured in collisions than skiers 34 vs. 58\% (8\% tubing or other activity). In 2010, two skiers and one snowboarder died, two of three were not wearing helmets. In 2013, another snowboarder died attempting to retrieve a snowboard. All four deaths involved catastrophic sliding falls in hard snow resulting in severe injuries that included the head.

The proportion of injuries attributed to jumps were $7.3 \%$; man-made terrain features $5.3 \%$; lift accidents $2 \%$; and sliding whilst tubing or other incident types accounted for the remaining $1.5 \%$. When considering mechanisms of injury using counts of injury types in each year there was a likely decrease in jump-related injuries $(0.83$, 99\% CI $0.69-0.99)$, likely trivial decrease in falls $(0.94,99 \%$ CI $0.88-$ $1.00)$ and the inference for collisions was unclear (1.00, 99\% CI 0.83-1.22).

In terms of sky cover, there was 2.5 times more likelihood of injury in good visibility conditions (hazard ratio 2.5, 99\% CI 1.97-3.19). In good visibility, advanced skiers most likely increased injuries to the lower leg when the snow was soft vs. hard (hazard ratio 2.06, CI 99\% 1.55-2.7) and a likely increased probability of knee injury in soft snow vs. hard (hazard ratio $1.28,99 \%$ CI 1.11-1.48). In poor visibility, the probability that advanced skiers injured the lower leg in soft snow vs. hard snow was a likely increase (hazard ratio 1.63 , CI 99\% 0.94-2.71). Soft snow conditions led to a very likely increase that advanced skiers sustained knee injuries (hazard 
ratio $1.59,99 \%$ CI 1.16-2.11). Intermediate skiers in good visibility had a very likely increase in lower leg injury (hazard ratio 1.34, CI 99\% 1.12-1.60); however, in poor visibility and soft snow the results were unclear (hazard ratio 1.02, CI 99\% $0.73-1.40$ ). For the knee, there was a very likely increase of injury in intermediate skiers when the visibility was good and the snow was soft (hazard ratio 1.27, CI 99\% 1.16-1.39). In poor visibility, intermediate skiers had a most likely increase of injury (hazard ratio 1.63, 99\% CI 1.38-1.89). Novice skiers had similar findings to intermediate skiers when the visibility was poor.

\section{Discussion}

New Zealand injury trends per 1000 skier/boarder days were higher than the 2.5 per 1000 skier/boarder days in the US National Ski Areas Association (NSAA) 10-year interval study (3.2, 3.3, 3.4, 2.7, and 3.1, respectively) [5]. An overall target of less than 2.5 injuries per 1000 skier/boarder days in New Zealand (SAANZ national incident data) is clearly desirable. There was no known reason for the decline of injuries in the 2013 season; this decline was not sustained. The influence of the snow-pack on injury incidence will need to be considered and accounted for in future statistical analysis so that the effectiveness of injury prevention interventions can be separated from natural events. More skiers than snowboarders were active on the slopes. The SAANZ customer satisfaction survey data (2007-2009) indicated that there were slightly more male skiers than females and that snowboarding was dominated by males. The lack of 2010-2014 demographic data is a potential limitation; however, major changes in the make-up of the snow sports population are unlikely.

Nearly one-third of NZ adult skier injuries involved the knee, with female skiers at greater risk of knee injury than males. These findings align with earlier studies [5-8]. Since the introduction of the carving ski in 1993, female skiers have dominated knee injury trends. For females, the risk of knee sprain was two to three times higher in females, and there was an even greater risk of anterior cruciate ligament rupture. Ski-binding release settings that were too tight were associated with knee and lower leg injury in all skiers $[9,10]$. One solution found to reduce knee and lower leg injuries was regular equipment torque testing and set-up checks [11]. To determine that ski-binding-boot systems are not too tight and that the ski equipment is working effectively, the snow sports industry in New Zealand need to invest in torque-testing equipment [12-16]. The analogy of an annual motor vehicle warrant of fitness could be used to encourage skiers to have ski equipment regularly torque tested and tuned.

Presently, there are no recommendations from standard organisations to account for snow surface conditions when setting up the ski-binding-boot system. Given the increased probability of injury to the lower leg and knee in soft snow, adjusted lower settings that promulgate release when skiing in soft snow surface conditions seem logical. The release results in this study add further weight to the need for vigilance 
during ski-binding set-up. Changes in weight, growth, and skiing style need to be factored into pre-season release setting calculations. Advanced skiers may no longer have the fitness level or the desire to ski at speed aggressively on steep pitch in all snow conditions and as such these changes in skiing style warrant lower ski-binding release settings. Further public education on safe ski-binding set-up is needed. Researchers working with ski equipment manufacturers also need to continue the quest for solutions that will protect the knee whatever the direction of the injurious force $[17,18]$.

Skiers and snowboarders had similar rates of back injury, with nearly two-thirds of these involving the lumbar/sacral region. An earlier New Zealand study in the Southern Lakes region (1991-2002) found a higher proportion of skiers had burst/ compression fractures when compared with snowboarders. The most frequently fractured vertebrae were found at the thoracic-lumbar junction at the posterior base of the rib cage $[19,20]$. The change in the injury pattern to the lumbar/sacral region is possibly due to the advent of twin tip skis and snowboards leading to more aerial manoeuvres. The Swiss found that the majority of severe spinal injuries $(n=63)$ admitted to a tertiary trauma centre were related to skiing, with over half of all spinal injuries sustaining injury at two or more levels [21]. Injury prevention interventions to decrease back injuries will need to consider the changes that have occurred in the way people ski and snowboard.

Helmets have been proven to dampen forces and protect the head from injury when skiing or snowboarding with no increased risk of neck injury [4, 22-26]. Helmets are designed to limit linear acceleration to no more than $300 \mathrm{~g}$ following a $2.0 \mathrm{~m}$ drop onto a steel surface (translating to $27.7 \mathrm{~km} / \mathrm{h}$ ). Helmets have been proven to reduce head abrasions, lacerations, and mild concussion [4]. The increase in concussion rates raises concern that those wearing helmets are overestimating the protective capacity of the helmet and are taking greater risks with speed and/or jump-height than those not wearing a helmet. More research is needed on risktaking behaviours $[27,28]$.

Death was attributed in-part or in-full to traumatic brain injury in the four tragedies at New Zealand ski areas. After the 2011 inquests for three of these deaths the Coroner recommended that ski areas actively promote the use of helmets when skiing or snowboarding (mandatory use was not included in the court summations). Helmet wear has been promoted in the SAANZ snow sports injury prevention strategy and the new snow safety code [29]. Further work is warranted on trends in head injury severity using Glasgow coma scale scoring (these head injury observations are entered in the patient report section of the SAANZ incident reporting form but not entered in the NID). To continue to improve the design of snow sports helmets further understanding of the torsional and coup-contrecoup forces that brain tissues are exposed to are also needed [30].

Other countries have found similarly high rates of wrist fractures in snowboarding as were reported in this study. Some researchers detailed up to a tenfold increase when compared snowboarding to skiing, with most wrist fractures occurring within the first 7 days of learning to snowboard [31-34]. We found that there was a very likely increase in wrist injuries in snowboarders that were intermediate and a pos- 
sible increase in novices in hard snow conditions. More education on safe techniques for riding in hard snow conditions is needed for intermediate and novice snowboarders. Development of a national snowboarder education programme has been promoted in the strategy to counter fall mechanisms that result in wrist fractures [31]. Wrist protection was clearly found to be beneficial in preventing wrist injuries. Presently, there is no international standard for snow sports wrist protectors. In New Zealand, some of the wrist protectors are potentially too short, finishing proximal to the wrist joint. Short wrist guards have the potential to transfer the force to forearm and cause breaks [35]. Further investment and promotion of wrist protection will occur in New Zealand when the international standard for snow sports wrist protectors has been agreed on [34].

Snow surface condition and visibility information informs ski area decisions on whether to open all runs. When runs are open regular updates on snow surface conditions matched to the ability are needed so that trail choices are a better match for the skier or snowboarder, particularly the novice and intermediate. When mountain weather conditions are changeable good vision is needed for hazard identification. The visual deficiencies created by foggy goggles, inappropriate lens colour, or no optical correction may account for injury on poor visibility days. Decreased visual acuity has been found to delay reaction-times and the ability to take evasive action [36-38]. Regular eye testing and wearing prescription eyewear whilst skiing or snowboarding has been included in the strategy. GPS mapping that pinpoints where incidents are occurring aligned with snow surface conditions and visibility information could also provide opportunities to mitigate injury. An increased provision of equipment-related information to at-risk groups such as check your set-up, sharpen edges for hard snow conditions, and choose the correct wax to help glide and reduce friction would also be of value [39].

\section{Conclusion}

Injury trends in snow sports in New Zealand indicate that there was no significant decline over five winters. Future injury prevention priorities need to be based on injury surveillance. Going forward, strategies will be needed to counter, "the higher or faster you go, the harder you fall" phenomena. The high proportion of advanced skiers and intermediate skiers with knee injuries that occurred with non-release in both hard snow and soft snow conditions raises concern that ski-binding release settings were too high. To help mitigate equipment-related injury risk skier education on correct set-up is needed alongside industry adoption of international equipment torque testing and practice standards. Knee injuries that occur skiing also beseech an equipment design solution. Using helmets unfortunately was not a panacea for decreasing the number of head injuries but likely reduced the gravity. Further research is needed on head injury to understand why those that are wearing helmets are suffering more head injuries than those that are not protected by a helmet. Risk compensation was one possible explanation. The ability to avoid hazards in poor 
visibility could potentially be enhanced by improving technique, regular eye testing, and for those that need it, wearing prescription eyewear on the snow. Wrist protectors were clearly of benefit in reducing wrist fractures in snowboarders. The release of the international snow sports wrist protector standard is eagerly awaited so that wrist protectors with the proven correct dimensions can be promoted. The four deaths that occurred were a sobering reminder that injury prevention efforts cannot diminish. No deaths would be a more than reasonable goal; however, due to human fallibility and the unpredictable challenges faced in mountain terrain this may never reach zero. The development of snowboard brakes could reduce risk of injury during retrieval of a runaway snowboard. Furthermore, when ski area staff open terrain for the public, full account needs to be taken of hard snow surface conditions that increase the risk of sliding falls.

\section{Limitations}

The SAANZ national customer satisfaction survey programme was discontinued in 2010. SAANZ reports for 2010-2014 estimated that these demographics were unchanged; however, there was no data provided to support this assumption. Changes in the make-up of the active snow sports population may have occurred over the years of this study. These surveys may also have had interviewer bias, with one group being interviewed more than another group. There was also no data on the number of people that declined to be interviewed. To effectively target at-risk groups, demographic data (skier, snowboarder, female, or male) needs to be routinely collected at ski areas on each day of operation and included in future analysis of National Incident Data.

Head injury and bare-head count data were only provided by two major ski areas. Counts are needed at all ski areas to more accurately determine the effect of increased helmet use.

Acknowledgements Heads of safety services, ski patrollers, and mountain clinic staff are gratefully acknowledged for their roles in collecting data. The executive of Ski Areas Association New Zealand and the New Zealand Mountain Safety Council are also acknowledged for providing central co-ordination and encouragement over the years of this study.

\section{References}

1. van Mechelen W, Hlobil H, Kemper HCG (1992) Incidence, severity, aetiology and prevention of sports injuries. A review of concepts. Sports Med 14(2):82-99

2. Hopkins WG, Marshall SW, Batterham AM, Hanin J (2009) Progressive statistics for studies in sports medicine and exercise science. Med Sci Sports Exerc 41(1):3-12

3. Marshall SW (2008) Injury case-control studies using "other injuries" as controls. Epidemiology 19(2):277-279 
4. Mueller BA, Cummings B, Rivara FP, Brooks MA, Terasaki RD (2008) Injuries of the head, face, and neck in relation to ski helmet use. Epidemiology 19(2):270-276

5. Shealy J, Ettlinger CE, Scher I, Johnson R (2014) 2010/2011 NSAA 10-year interval injury study. J ASTM Int 20:93-111

6. Laporte JD, Binet MH, Constans D (2000) Evolution of ACL ruptures in French ski resorts 1992-1999. J ASTM Int 13(STP 1397):95-107

7. Greenwald R, Senner V, Swanson S (2001) Biomechanics of carving skis. Schweizerische Z Sportmed Sporttraumatol 49(1):40-44

8. Ruedl G, Linortner I, Schranz A, Fink C, Schindelwig K, Nachbauer W et al (2009) Distribution of injury mechanisms and related factors in ACL-injured female carving skiers. Knee Surg Sports Traumatol Arthrosc 17(11):1393-1398

9. Laporte JD, Binet MH, Bally A (2003) Why the ski binding international standards have been modified in 2001. J ASTM Int 14(STP 1440):64-94

10. Laporte JD, Binet MH, Fenet N, Constans D, Joubert P (2008) Ski bindings and lower leg injuries: a case control study in Flaine 2006. J ASTM Int 17(STP 1510):77-88

11. Costa-Scorse BA, Hopkins WG, Bahr R (eds) (2015) Evaluation of ski-binding-boot system safety using torque testing. ASTM Special Technical Publication, West Conshohocken

12. Costa-Scorse BA, Hopkins WG, Bahr R, Lamont M (eds) (2015) Translation of international snow-sports equipment standards into injury-prevention practice. ASTM Special Technical Publication, West Conshohocken

13. ISO-11088:2006(E). Assembly, adjustment and inspection of an alpine ski-binding-boot (S-BB) system. International Organization for Standardization, Geneva

14. ISO-13993:2001(E). Rental ski shop practice-sampling and inspection of complete and incomplete alpine ski-binding-boot systems in rental applications. International Organization for Standardization, Geneva

15. F-1063-03. Standard practice for functional inspections and adjustments of alpine ski-bindingboot systems. ASTM International, West Conshohocken

16. F-1064-03. Standard practice for sampling and inspection of complete and incomplete alpine ski-binding-boot systems in rental applications. ASTM International, West Conshohocken

17. Senner V, Michel FI, Lehner S, Brügger O (2013) Technical possibilities for optimising the ski-binding-boot functional unit to reduce knee injuries in recreational alpine skiing. Sports Eng 16(4):211-228

18. Senner V, Michel FI, Lehner S (2013) Ski equipment-related measures to reduce knee injuries. Swiss Council for Accident Prevention, Berne

19. Donald S, Chalmers D, Theis J-C (2005) Are snowboarders more likely to damage their spines than skiers? Lessons learned from a study of spinal injuries from the Otago skifields in New Zealand. N Z Med J 118:U1530

20. Bianchi G, Michel FI, Brügger O (2012) The use of wrist guards by snowboarders in Switzerland. J ASTM Int (STP 1553):38-53

21. Bianchi G, Brügger O, Niemann S, Cavegn M (2011) Helmet use and self-reported risk taking in skiing and snowboarding. J ASTM Int 8(1):1-8

22. Scher I, Richards D, Carhart M (2006) Head injury in snowboarding: evaluating the protective role of helmets. J ASTM Int 3(4):1-9

23. Sulheim S, Holme I, Ekeland A, Bahr R (2006) Helmet use and risk of head injuries in alpine skiers and snowboarders. J Am Med Assoc 295(8):919-924

24. Scher I, Richards D, Carhart M, Thomas R, Hurlen N, Lam T (2009) Pediatric head and neck injuries in snow sports: evaluating the influence of helmets. ASTM Special Tech Publ 5(4):91-107

25. Hagel BE, Russell K, Goulet C, Nettel-Aquirre A, Pless IB (2010) Helmet use and risk of neck injury in skiers and snowboarders. Am J Epidemiol 171(10):1134-1143

26. Shealy JE, Johnson RJ, Ettlinger CE (2006) On piste fatalities in recreational snow sports in the US. ASTM Special Tech Publ 3(5):27-34

27. Scott MD, Buller DB, Andersen PA, Walkosz BJ, Voeks JH, Dignan MB, Cutter GR (2007) Testing the risk compensation hypothesis for safety helmets in alpine skiing and snowboarding. Inj Prev 13:173-177 
28. Ruedl G, Abart M, Ledochowski L, Burtscher M, Kopp M (2012) Self-reported risk taking and risk compensation in skiers and snowboarders are associated with sensation seeking. Accid Anal Prev 48:292-296

29. Costa-Scorse B, Hoyle A, Davidson M, Dooney A, Clinton-Baker P, Lamont M, et al. (2015) New Zealand snow sports injury prevention strategy (2015-2020) - a snow sports industry initiative. Wellington, New Zealand: Ski Areas Assoc New Zealand

30. Dickson TJ, Trathen S, Waddington G (2011) Investigating characteristics of head impacts in paediatric snowsport participants: using telemetry, GPS positioning and acceleration logging. Procedia Eng 13:476-480

31. Cooper N, Greenwald R (2006) Observational study on fall trends in snowboarding. J ASTM Int 3(5): 19-25

32. Kim S, Endres NK, Johnson RJ, Ettlinger CF, Shealy JE (2012) Snowboarding injuries: trends over time and comparisons with alpine skiing injuries. Am J Sports Med 40:770-776

33. Russell K, Meeuwisse WH, Nettel-Aguirre A, Emery CA, Wishart J, Romanow NTR et al (2014) Feature-specific terrain park-injury rates and risk factors in snowboarders: a casecontrol study. Br J Sports Med 48(1):23-28

34. Michel FI, Schmitt KU, Greenwald RM, Russell K, Simpson FI, Schulz D et al (2013) White paper: functionality and efficacy of wrist protectors in snowboarding-towards a harmonized international standard. Sports Eng 16(4):197-210

35. Lehner S, Geyer T, Michel FI, Schmitt KU, Senner V (eds) (2014) Wrist injuries in snowboarding: simulation of a worst case scenario of snowboard falls. Procedia Eng 72:255-260

36. Jendrusch G, Senner V, Schaff P, Heck H (1999) Vision—an essential factor for safety in skiing: visual acuity, stereoscopic depth percetion, effect of colored lenses. J ASTM Int 12(STP 1345):22-34

37. Senner V, Jendrusch G, Schaff P, Heck H (1999) Vision-an essential factor for safety in skiiing: perception, reaction, and motion control aspects. J ASTM Int 12(STP 1345):11-22

38. Harley E, Scher I, Stepan L, Young DE, Shealy J (2010) Reaction times of skiers and snowboarders. J ASTM Int 18(STP 1525):90-98

39. Coupe RC, Spells SS (2010) Towards a methadology for comparing the effectiveness of different alpine ski waxes. Sports Eng 12:55

Open Access This chapter is distributed under the terms of the Creative Commons AttributionNoncommercial 2.5 License (http://creativecommons.org/licenses/by-nc/2.5/) which permits any noncommercial use, distribution, and reproduction in any medium, provided the original author(s) and source are credited.

The images or other third party material in this chapter are included in the work's Creative Commons license, unless indicated otherwise in the credit line; if such material is not included in the work's Creative Commons license and the respective action is not permitted by statutory regulation, users will need to obtain permission from the license holder to duplicate, adapt or reproduce the material. 